\title{
A Study on C-E Translation of Xi'an Regional Culture
}

\author{
Chen $\mathrm{Ke}^{1 \mathrm{st}}$ \\ College of Foreign Languages \\ Xi'an Shiyou University \\ Xi'an, China \\ kechen.112233@163.com
}

\author{
Yang Fangfang ${ }^{2 n d}$ \\ College of Foreign Languages \\ Xi'an Shiyou University \\ Xi'an, China \\ 1418684304@qq.com
}

\begin{abstract}
This paper, through a detailed research on the problems existed in $\mathrm{C}$-E translation of $\mathrm{Xi}$ 'an regional culture, points out that the main reasons are: lack of the equivalence on cultural exchange and lack of cooperation between the government and non-government communities. To resolve misunderstanding from cultural backgrounds, social customs as well as thought patterns, we try to present some translation strategies which include trans-editing strategy, anaphora resolution strategy, substitutive strategy, fixed translation strategy and structure rearrangement strategy. Owing to the unique cultural status Xi'an has been included in the Silk Road Construction, we should set our cultural publicity research in a cross-language, cross-cultural environment; then we can propose some countermeasures as follows: to highlight the local culture core values; to strengthen the government functions in cultural administration; to encourage non-governmental organizations' participation in the cultural industry research and translation; to strengthen the training of media and practitioners in culture publicity translation.
\end{abstract}

Keywords-C-E Translation; Regional Culture; Translation Strategies; Core Value

\section{INTRODUCTION}

A regional culture is a culture in which a particular group of people share a similar environment and language. C-E translation, the short form of Chinese-English translation for overseas publicity, is affected deeply by regional culture value and social ideology due to its unique status in social, political and economic life [1]. Without regional culture elements, it is hard to express the practical value and theoretical significance of C-E translation [2].

\section{POSITION AND CONTENT OF XI'AN REGIONAL CULTURE}

\section{A. Position of Xi'an regional culture}

The proposal on strategic concept of the Silk Road Economic Belt is regarded as a new stage of Western China Development. To meet the needs of this historical opportunity, $\mathrm{C}-\mathrm{E}$ translation of $\mathrm{Xi}$ 'an regional culture, bearing the characteristics of spreading cultural values apart from message communication, shoulders the important task of publicizing regional culture to the world. Xi'an is a friendly modern city with wealthy ancient civilization, so undoubtedly its cultural diversity should be the first focus. But in the eyes of many foreigners, their images of the city still stays in the Terra-cotta warriors and the Yellow Land owing to their poor knowledge of Xi'an modern civilization. Therefore, C-E translation of $\mathrm{Xi}$ 'an regional culture, plays an important role in promoting local economy, building city's image, as well as expressing the traditional cultural and highlighting its distinct characteristics.

\section{B. Content of Xi'an regional culture}

The construction of Silk Road Economic Zone, a long-term task, needs a process of sustainable development, so we never expect it can be accomplished overnight. It offers a wide range from cultural exchange to economic cooperation, and the content of $\mathrm{Xi}$ 'an regional culture includes:

1) City cultural image with its own characteristic

City cultural image refers to the appearance of the city, which includes modern infrastructure and fashionable appearance, such as the spatial arrangement, architectural image, style color and road, plaza, park, sculpture, street lamps, railing, or even street signs, advertising and so on. Image culture is the material carrier and guarantee for urban culture. Paris, and many famous cultural cities such as London, Mosley, Frankfurt, Venice, has their own unique urban cultural image, therefore, only one or two iconic cultural facilities can increase the whole city's cultural taste.

2) Historical and cultural resources with inheritance and significance

Historical and cultural resources, expression of cultural taste of the city, reflects not only culture personality, but also cultural predominance. For example, Florence, a notable cultural and historical city of Italy, is popular with the famous person as Dante Michelangelo, leonardo Da Vinci, etc. so does Xi'an. We can also take advantage of our celebrities to spread regional culture. 


\section{3) Modern and prosperous culture industry}

A cultural industry means the gather of the industries that $p$ rovide the product and services of culture and entertainment for social public and other related industries. It can effectively promote local economic development and improve its cultural taste. Los Angeles, American city, is famous for its Disneyland and Hollywood so as to form the first class audio-video products industry and cultural tourism industry. Nowadays a lot of cities in France, the United States, Japan and South Korea, set the culture industry as pillar industry for city economy. Also in China, big cities as Beijing, Shanghai, Guangzhou, Shenzhen, give the priority to cultural industry.

\section{4) Colorful folk culture}

Xi'an folk culture has its own
of particular regional economy and national historical culture. It features in the forms of culture between citizens, campus culture, enterprise culture, and community culture, especially festivals culture. Folk culture is an important part of city culture as well as city value. For example, the Olympic Games makes Barcelona famous all over the world; Weifang, a small city in Shandong, due to its international Kite-flying festival each year, is also well-known at home and abroad. Large festival culture activities can raise awareness of the city.

\section{STATUS AND PROBLEMS ON C-E TRANSLATION OF XI'AN REGIONAL CULTURE}

With the popularization of exchanges and cooperation with foreign countries, establishing an omni-directional, multilevel and wide-range culture exchange is imminent. Therefore, publicity materials play an outstanding role in popularizing regional culture. From the government documents, economic and trade fair activities to street signs, advertising, television, newspaper, C-E translation appears in nearly all walks of life.

But the current quality of Xi'an C-E translation is not optimistic, and there still exists much room for improvement. We found many errors in the content of foreign publicity, publicity brochures posters, exhibition information and public signs. Unqualified or wrong translation will not only popularize regional culture, but also easily makes foreigners confused and puzzled, which directly affects the external image of Xi'an, and may even produce far-reaching harmful influence that nothing can compensate.

\section{A. Status of C-E translation on Xi'an regional culture based on questionnaire survey}

In order to confirm the quality and effect of C-E translation of $\mathrm{Xi}$ 'an regional culture, we designed an experiment which is based on the questionnaire, observation and personal interview; it can overcome the shortcomings by intuition and experience in the past, contributing the approach on regional culture publicity translation from empirical research to high level of scientific theory, and it will be an effective way to evaluate its status and then find countermeasures on $\mathrm{C}-\mathrm{E}$ translation of Xi'an regional culture.

Research methods: This study selected 36 international students from Xi'an Shiyou University, 100 college students and 30 foreigners of Xi'an as a sample.
Research object: The object of this research is 36 international students, 100 college students and 30 foreigners.

Research tools: The tool of this research is questionnaire, namely "Status on C-E translation of Xi'an regional culture". Here introduces the intention of content and the design of questionnaire.

Data collection and analysis: The questionnaire is sent and reclaimed in the form of e-mail. The questionnaire data are analyzed through SPSS software. After semantic experimental analysis on a number of respondents and data processing, we can draw a conclusion as the following shows.

1) Cultural value would be core factor in C-E translation.

The world economic integration promotes the integration of world culture to meet the needs of its development. However, during the cultural exchange, the economic inequality will result in the political inequality because the stronger economic culture deprives the weaker culture's own characteristics, at last the weaker one is confronted to the risk of being assimilation. Making a comparison between these two kinds of culture, Chinese culture stands an obvious deficit position. The strong culture produced by English, gradually infiltrated the Chinese cultural tradition, quietly changed our cultural pattern. When there exists culture collision, their own language will be first influenced. Today some European expression is very popular among the Chinese, or even has the tendency to be the mainstream. If the culture difference can even bring the change to the language system, it means that the whole nation is undefended. If regional culture does not want to be replaced by another culture, cultural value would be core factor in $\mathrm{C}-\mathrm{E}$ translation.

2) C-E translation represents its level of foreign exchange and human environment.

Incorrect or non-standard translation errors can be seen everywhere, from image window units as hotels, restaurants, tourist attractions or the pavilion to public places as parks, street, mall. Part of the reason is that the translator have biased understanding to the materials, and part is due to lack of adjustment and modification to the context, and some even because of translator's carelessness. But in essence, we are short of a regulatory departments to be responsible for conducting overall plan, general coordination and macro management on translation quality and level. If before these materials are available, a regulator can review them to avoid the occurrence of translation errors, the situation will be much better. In short, relevant regulatory authorities have not focused enough on this phenomenon.

\section{B. Problems on C-E translation of Xi'an regional culture}

In order to get the detailed information about $\mathrm{C}-\mathrm{E}$ translation of Xi'an regional culture, we used nearly six months (January 2017 to June 2017) to make a massive investigation and collection on publicity translation of hotels, shopping malls, restaurants, scenic spot, agencies, railway stations, airports, sites and other places in Xi'an and its surrounding areas; we also did the similar job (February 2014 to July 2014) in London and its suburbs Reading Town (Reading). Then through the comparison with native language city, we can get 
an objectively result on the Status and problems existed in C-E translation of Xi'an regional culture.

\section{1) lack of the equivalence on cultural exchange}

Due to lack the equivalence of cultural exchange, $\mathrm{C}-\mathrm{E}$ translation cannot embody Xi'an regional cultural characteristics, so limits its influence on Westerners. If we still blindly satisfy the need of "the target language readers", only to meet and maintain their own cultural identity, we will lose our own cultural characteristics. The current existing inequality in cultural exchanges will do harm to the improvement of Xi'an regional culture. In the long run, our own cultural values will be weakened, and even be a victim of the language invasion.

2) Lack of cooperation between the government and the academic and cultural communities

With no cooperation between the government and the academic and cultural communities, C-E translation of Xi'an regional culture is completely independent, which leads to the translation disunity on its contents, that is why the translation on the same agencies, the same event, the same places are not identical, which results in negative influence on cultural exchange and transmission.

\section{IV. STRATEGIES AND COUNTERMEASURE ON C-E TRANSLATION OF XI'AN REGIONAL CULTURE}

\section{A. Strategies on C-E translation of Xi'an regional culture \\ 1) Trans-editing strategy}

As the object of C-E translation is target audience, readers who come from different social and cultural background must have their own way of thinking. If we want they can recognize, understand and even accept our translated version, we should not only focus on the difference between internal and external culture, but also the difference among external cultures. Transediting process is actually a secondary process. Under the premise of grasping the original spirit and connotation, the translator can cut down the insignificant things in the original text, add the necessary background material, and even adjust and reorganize the original texts.

\section{2) Anaphora resolution strategy}

Due to the fact that each nation has its own different historical realities and cultural background, there will be a large number of terminology with its own national characteristics. In the translation of these terminology or special words, anaphora resolution strategy may be adopted. Consequently, the object of translation is no longer the source language, but the message conveyed in the form of language. In this way, the evaluation criteria can be divided into four levels: the level of language organization, language flu, intonation and other inappropriate information organization, timely feedback on the communicative effect. Generally speaking, we must clearly understand the source language. Especially during the process of C-E translation, we should not only understand the original text, but also the information hidden behind the original cultural background and political history. The so-called political history refers to the historical background of a policy. Then through the overall grasp, we can take the original text and text behind the ideological feelings, cultural images, social background, the baseline mood into our translation consideration.

\section{3) Substitutive strategy}

There exist great differences between English and Chinese. In Chinese, repetition can be used to balance the content, to render the atmosphere and to emphasize the role of tone. While in English, owing to its rhetorical methods and structural reasons, they prefer pronouns to the above-mentioned parts to avoid semantic meaning repeat. American translation theorist Nida put forward the concept of "functional equivalence" in the 1960s, that is, translation should be based on "functional equivalence" that reflects "deep structure", rather than "formal correspondence" of "surface structure"[3]. Cohesion in English, a collaboration between Halliday and Hassan, moves linguistic analysis beyond the sentence level to the discourse level. Many linguists introduce convergence theory into translation practice.

\section{4) Fixed translation strategy}

International reports aim at conveying information and promoting exchanges so that foreigners can better understand China's past, present and future development. In the process of $\mathrm{C}-\mathrm{E}$ translation, the unification of translations, especially the unification of proper nouns in Chinese, is the key link in translation work. Without the unification of translations, the effect of C-E translation will naturally be reduced, and it will puzzle the reader, then result in misunderstanding.

In August 1981, the International Organization for Standardization passed a resolution, which claimed that "Chinese phonetic alphabets" can be used as an international standard for spelling out the names and terms of Chinese; in addition, the translated terms which have been used for years should not be re-translated to avoid creating new chaos. For $\mathrm{Xi}$ 'an, the urgent task at present is to regulate the names of places, especially traffic sign names. Otherwise, it is not conducive for the foreigners to learn, sightseeing and invest in this city.

\section{5) Structure rearrangement strategy}

Structure rearrangement method is also called rewriting method, that is, the translator grasps the essence of the original text, then restores the content and structure of the original text by subtracting, supplementing, reorganizing and other methods, to enhance the readability and acceptability of the translation as well as reduce Chinese English and translation Cavity[4]. Reconstruction includes the reconstruction of the title, reconstruction of sentence order and and reconstruction of discourse pattern [5]. The Chinese way of thinking is characterized by intuition, concreteness and roundness. Therefore, the composition of Chinese discourse often adopts the inductive reasoning method of "side-knocking" and "omission". While Westerners pay more attention to linear causal thinking, they prefer straight-to-the-point deductive reasoning way. A C-E translators, sometimes only need to make the simple deletion and addition, sometimes need to make dramatic adjustments and reconstruct them at the discourse level in order to meet the needs of target audience. The Chinese like comprehensive thinking way, and emphasize the curvilinear method, which is manifested in the discourse organization; usually, the method of "concrete-inductive" and 
the structure of "flowing" sentence are adopted. Western readers like analytical thinking way, which is also reflected in the discourse organization; usually the method of "deductive reasoning" and "tree-shaped" sentence structure are adopted [6].

For example, our government work report is intended to better explain Xi'an to the world and publicize the Xi'an government's position. Xi'an government work report mainly consists of three aspects: a review of government work in the past year; basic ideas, tasks and objectives of the Five Year Plan Development; main targets in this year. Its translation should also be fairly consistent with the source language, that is: to comply with the formal style of political essay written style, and to highlight its preciseness, conciseness, standardization and accurateness. From the perspective of communicative function of discourse, it belongs to the discourse which is dominated by information transmission, and interspersed with the arguments. Due to the large size of the English characters and the large space, it is necessary to find ways to save space when writing in the limited space. Therefore, the headlines of English should be short in words, and omit the functional words such as the linking verbs, auxiliary verbs, conjunctions, articles and so on. In order to give prominence to the real-time report, the English title should be translated within one line, and a variety of typographic means, such as bold, normal, italics, etc. can be used; while Chinese characters occupy a small space, because limited words can express rich meaning, and the same space can accommodate more content, as a result, Chinese news headline will be more focused on the choice of words or rhythm and the symmetry of its delivery.

\section{B. Countermeasure of $C$-E translation on Xi'an regional culture}

For the practical problems appearing during the process of $\mathrm{Xi}$ 'an regional culture publicity translation at present, if any improvement we want to achieve, government regulators, translators, non-governmental organizations and cultural, scientific community must have enough cooperation.

\section{1) To highlight the local culture core values}

Constructing our own open and inclusive publicity translation system, we can integrate Xi'an rich cultural resources, highlight the city cultural creativity, and create local cultural brand. To improve the urban competitiveness and regional culture influence, we should focus on a characteristic, reasonable publicity translation system. Scratch the surface of $\mathrm{Xi}$ 'an rich culture and heritage, you will be amazed at its diversity: rich historic culture of thirteen dynasties, multiple coexisting religious culture, and inclusive modern culture industry.

2) To strengthen the government functions in cultural administration

The government of Xi'an city must be pragmatic and efficient, and organize clear-targeted research on basic status and existing problems of Xi'an regional culture publicity translation, so as to allocate various resources rationally, regulate standard system of cultural industry associations.
Apart from giving them funds and policy support, the city government should also set unified and regulatory standards.

3) To encourage non-governmental organizations, participation in the cultural industry research and translation

Encourage more academic and cultural communities to participate in the cultural industry research and translation, and strengthen the supervision over the quality of translation. Enhance the whole society's awareness on traditional publicity culture translation, and convey our cultural information, so as to show unique charm of $\mathrm{Xi}$ 'an regional culture, and avoid cultural resistance from the western society.

4) To strengthen the training of media and practitioners in culture publicity translation

Build up a translation team with high cultural quality and strong language skills. Because the object of C-E translation has a totally different language and culture background and ideological values, translators not only need to fully understand traditional cultural background of the target language audience, but also can accurately grasp the essence of Xi'an regional culture. Only in this way can we precisely convey thought and value that our culture contains.

\section{CONCLUSION}

C-E translation on Xi'an regional culture is a complex process that involves language, culture, psychology, politics, and many other aspects. Owing to the unique cultural status Xi'an has in the Silk Road Construction, we should set our cultural publicity research in a cross-language, cross-cultural environment, and highlight our core values, to realize the cooperation between the government and academic, cultural communities.

\section{ACKNOWLEDGEMENT}

Scientific Research Program Funded by Shaanxi Provincial Education Department (Program "A study on C-E Translation of Xi'an Red Tourism Texts from the Perspective of Translation as Adaptation and Selection)

\section{REFERENCES}

[1] Bassnett, S. 2001. Translation studies. Shanghai: Shanghai Foreign Language Education Press.

[2] Dryden, J. 2006. Western translation theory: from herodotus to nietzsche. Beijing: Foreign Language Teaching and Research Press.

[3] Nida, E. A. Language and Culture: Contexts in Translating [M]. Shanghai: Shanghai Foreign Language Education Press, 2001.

[4] Newmark, P. Approaches to Translation [M]. New York: Prentice Hall International (UK) Ltd., 1988.

[5] Nord, C. Translating as a Purposeful Activity: Functionalist Approaches Explained [M]. Shanghai: Shanghai Foreign Language Education Press,2001.

[6] Reiss, K. Translation Criticism: Potential \& Limitations [M]. Shanghai: Shanghai Foreign Language Education Press,2004. 